\title{
Observed Shear-Relative Rainfall Asymmetries Associated with Landfalling Tropical Cyclones
}

\author{
Xiang Wang, ${ }^{1,2}$ Haiyan Jiang, ${ }^{2}$ Xun Li $\mathbb{D}^{3},{ }^{3}$ and Jun A. Zhang ${ }^{4}$ \\ ${ }^{1}$ Joint Centre for Data Assimilation Research and Application, Institute for Climate and Application Research, \\ Nanjing University of Information Science and Technology, Nanjing, China \\ ${ }^{2}$ Department of Earth and Environment, Florida International University, Miami, FL, USA \\ ${ }^{3}$ Key Laboratory of South China Sea Meteorological Disaster Prevention and Mitigation of Hainan Province, \\ China Meteorological Administration, Haikou, China \\ ${ }^{4}$ NOAA/AOML/Hurricane Research Division, Cooperative Institute for Marine and Atmospheric Studies, University of Miami, \\ Miami, FL, USA \\ Correspondence should be addressed to Xun Li; cyrilpat@sina.com
}

Received 18 February 2020; Accepted 1 March 2021; Published 10 March 2021

Academic Editor: Hisayuki Kubota

Copyright (C) 2021 Xiang Wang et al. This is an open access article distributed under the Creative Commons Attribution License, which permits unrestricted use, distribution, and reproduction in any medium, provided the original work is properly cited.

\begin{abstract}
This study examines the shear-relative rainfall spatial distribution of tropical cyclones (TCs) during landfall based on the 19-year (1998-2016) TRMM satellite 3B42 rainfall estimate dataset and investigates the role of upper-tropospheric troughs on the rainfall intensity and distribution after TCs make a landfall over the six basins of Atlantic (ATL), eastern and central Pacific (EPA), northwestern Pacific (NWP), northern Indian Ocean (NIO), southern Indian Ocean (SIO), and South Pacific (SPA). The results show that the wavenumber 1 perturbation can contribute $\sim 50 \%$ of the total perturbation energy of total TC rainfall. Wavenumber 1 rainfall asymmetry presents the downshear-left maxima in the deep-layer vertical wind shear between 200 and $850 \mathrm{hPa}$ for all the six basins prior to making a landfall. In general, wavenumber 1 rainfall tends to decrease less if there is an interaction between TCs and upper-level troughs located at the upstream of TCs over land. The maximum TC rain rate distributions tend to be located at the downshear-left (downshear) quadrant under the high (low)-potential vorticity conditions.
\end{abstract}

\section{Introduction}

Landfalling tropical cyclones (TCs) can bring strong winds and heavy precipitation, which cause tremendous damage to the affected region [1]. Besides, flash flooding and landslides associated with long-duration rainfall of landfalling TCs have been the predominant causes of death all over the world [2]. The devastated regions are largely determined by the distribution of rainfall in landfalling TCs [3]. Skillfully forecasting the locations of extreme rainfall from TCs in advance is therefore urgently important in disaster mitigation and remains a highly challenging task $[4,5]$.

Earlier studies revealed that the mean rain rate in the TC eyewall increased as the storm intensified by using airborne radar datasets. Marks [6] showed that Hurricane Allen (1980) exhibited an azimuthal mean rain rate greater than
$11 \mathrm{~mm} \mathrm{~h}^{-1}$ in the eyewall, which was six times more than that within a radius of $111 \mathrm{~km}$ of mature Allen's center. Burpee and Black [7] found that the eyewall of Hurricane Alicia (1983) became circular as the maximum low-level winds approached $50 \mathrm{~m} \mathrm{~s}^{-1}$, while a second eyewall had shaped outside the original eyewall when the minimum central surface pressure dropped to $970 \mathrm{hPa}$.

However, the TC rainfall distribution can vary significantly from nearly axisymmetric to asymmetric under the influences of the storm dynamics and its environment over the open ocean. Asymmetries in TC circulations can be mainly induced by the effects of the storm motion [8-10], environmental deep-layer vertical wind shear (VWS) [11-19], and environmental flows interactions with the storm [20-24]. The rainfall maximum within the inner core region is generally located in down-motion flanks, which 
results from the friction-induced asymmetric boundary layer convergence, particularly to the right of motion $[8,11]$. The rainfall front maxima shifted to the front-right as the storm translation speed increased in North Atlantic or North Indian basin TCs composite by using satellite-based observations $[10,25]$. With satellite data from the Tropical Rainfall Measuring Mission (TRMM), the TC rainfall was depicted as the sum of an azimuthal mean (or a wavenumber 0) component and a significant spatial asymmetric variability (or a series of lower-wavenumber components) [16]. Though the dominant wavenumber 1 asymmetry is observed, some studies [18, 26] have suggested that higher wavenumbers $(>1)$ perturbations may also have potentially significant contributions using the Fourier decomposition method. For instance, Zhu et al. [26] documented that the energy from wavenumbers 1 to 6 contributed a large amount of energy to the total perturbation field of potential vorticity in a numerical modeling study, while Chen et al. [18] also found that though wavenumber 1 is dominant, wavenumber 2 rainfall asymmetry still contributes half of the amplitude of wavenumber 1 asymmetry. Pei and Jiang [27] found that the maximum motion-relative precipitation asymmetry is generally located down-motion but shifts cyclonically after adding the components of wavenumbers 2 through 6 to wavenumber 1 . Besides, they found that the maximum rainfall became pronounced at the front-left flank for tropical storms and front-right for major TCs. The TC motion is mainly determined by the steering flow that is affected by VWS [28]. The rainfall spatial distribution associated with VWS was examined both observationally and numerically. The results showed that VWS was a more dominant factor than the storm motion in producing downshear and left-of-shear precipitation or convection asymmetry when VWS is greater than $10 \mathrm{~ms}^{-1}$, especially for wavenumber 1 component [11, 15, 17-19, 27, 29]. Moreover, the rainfall asymmetries decreased with increasing TC intensity $[16,18]$.

Asymmetries in the TC rainfall associated with landfalling can be modulated by not only VWS [30-34], but also some other factors, such as nonuniform surface features including land-sea contrast and local topographic effect $[31,32,34-39]$ and interaction between TCs and synoptic weather systems $[38,40,41]$. In general, the landfalling TCs regularly had an asymmetry with a downshear to downshear-left rainfall maximum near the coastal regions, which is consistent with the studies for TCs over the ocean $[3,19,42]$. Yu et al. [30] found that the asymmetric rainfall maxima were more frequently located upshear and onshore in weak VWS environments. In fact, the effects of VWS and synoptic environment on TC rainfall asymmetry are not independent. The VWS with varying magnitude and direction promotes a different impact on TC rainfall or convection. Wingo and Cecil [43] noted that strong westerly shear was likely to form more asymmetric rainfall patterns than those of strong easterly shear. Some studies found that the dry air intruded to the right side of the shear vector was more adverse to the TC symmetric circulation [21, 38, 44, 45]. $\mathrm{Xu}$ et al. [42] presented that the rainfall percentage towards the right quadrant relative to the coastline would exhibit an obvious increase in prelandfall TCs near landfall in the eastern part of USA, which might be induced by the northward recurving of the storm towards the coast where the land-sea roughness gradient is present. However, TC rainfall enhancement induced by topographic effect was not evident in other landfalling TC studies $[32,42]$. Feng and Shu [37] showed that TC experienced a decrease in rainfall intensity during its landfall due to the cutting-off of energy and moisture from the ocean. In contrast, TC rainfall redistribution can be promoted by the interaction between a TC and baroclinic systems. As a midlatitude trough approaches landfalling TCs at the eastern part of USA from the northwest, potential vorticity redistribution through diabatic heating process acts to enhance the downstream of the TCs; Hurricane Sandy (2012) is such an example [41].

The overall goal of this study is to investigate the impacts of upper-tropospheric troughs on the asymmetric rainfall distribution and intensity during the life cycle (off-shore, during, and after landfall) of TCs making landfall from basin to basin with the Fourier decomposition method. Section 2 provides a description of the data and methods applied in this study. The shear-relative rainfall distribution and the effects of the upper-level trough on the rainfall intensity and asymmetric rainfall distribution are presented in Section 3. The conclusions are summarized in Section 4. Using a large sample of satellite-derived rain rates data set, we attempt to quantify asymmetry of the global landfalling TC precipitation with respect to the upper-level trough.

\section{Data and Methodology}

2.1. Data. The rainfall estimates taken from 19-year (1998-2016) TRMM 3B42 version 7 dataset are used in this study since 3B42 dataset could provide quite a reasonable rainfall pattern in landfalling TCs when compared with the gauge data or radar estimates [46-49]. TRMM 3B42 has a three-hourly temporal resolution and $0.25^{\circ}$ by $0.25^{\circ}$ spatial resolution, covering the globe from $50^{\circ} \mathrm{S}$ to $50^{\circ} \mathrm{N}$.

The TCs best-track data, including maximum sustained wind speed and storm center location, are provided by the Joint Typhoon Warning Center (JTWC) and the National Hurricane Center (NHC). Six TC-prone basins are included in this study: Atlantic (ATL), eastern and central Pacific (EPA), northwestern Pacific (NWP), northern Indian Ocean (NIO), southern Indian Ocean (SIO), and South Pacific (SPA).

The European Center for Medium-Range Weather Forecasts interim reanalysis (ERA-Interim; Dee et al. $[50,51])$ with a horizontal grid spacing of $0.25^{\circ} \times 0.25^{\circ}$ and a six-hour interval output is used to calculate the environmental vertical wind shear that is defined as the difference between the averaged wind vectors at the 850 and $200 \mathrm{hPa}$ levels. Following the approach used by prior studies [52-54], the horizontal wind vectors are averaged within a ring of $500-750 \mathrm{~km}$ from the TC center to avoid the influence of the storm's circulation as much as possible.

Many previous studies have utilized the potential vorticity (PV) to investigate the TC-trough interactions 
$[20,41,55,56]$, suggesting that an upper-tropospheric trough (characterized by PV anomaly) may play a key role in the TC development $[55,57]$. While several studies have documented that TC-trough interaction favors intensification [56,58], troughs could be unfavorable for TC intensification if the environmental wind shear is increased by a trough [59]. To evaluate the effects of different troughs on TCs developments, upper-tropospheric PV anomaly was used as a parameter to quantify the characteristics of troughs by Fischer et al. [55]. They used a simple objective technique to assess if a TC was interacting with an upper-tropospheric PV anomaly. Following Fisher et al.'s study, we aim to clarify the effects of upper-tropospheric trough on the asymmetric rainfall distribution during the life cycle of landfalling TCs in different basins. The $350 \mathrm{~K}$ isentropic surface PV anomaly is used to assess whether TCs are embedding with the upperlevel trough or low system in this study. The base state used to calculate the anomalies is a 30-day mean, centered on the $\mathrm{TC}$ time. If a PV anomaly with a maximum magnitude greater than 0.5 (less than -0.5 ) PVU in north (south) hemisphere exists anywhere within $500 \mathrm{~km}$ from the TC center and the maximum PV anomaly is located at the upshear side of the TC, the TC is considered to be embedded in an upper-level trough environment, hereafter denoted as "high-PV." In contrast, there is a less efficient TC-trough configuration, hereafter denoted as "low-PV."

Considering that the TC translation speed might vary significantly and following Xu et al.'s (2014) definition, we define four subregions on the basis of the proximity to the coast in this study, including (1) off-shore TCs, still far away from the coast $(300-700 \mathrm{~km}),(2)$ preland TCs, close to landfall $(0-300 \mathrm{~km}),(3)$ high-PV TCs after landfall $(-300$ to $0 \mathrm{~km}$, in-land) embedded in an upper-level trough environment, and (4) low-PV TCs after landfall ( -300 to $0 \mathrm{~km})$ under low-PV environmental condition. Table 1 lists the landing TC six-hourly samples in each subregion over the six basins during 1998-2016. As expected, the samples in all the subregions over NWP are much larger than other basins, since there are much more landfalling TCs over NWP. Alternatively, in-land TCs under high-PV condition are less than those under low-PV conditions for all the basins.

2.2. Rainfall Analysis Method. The TC rainfall distribution was analyzed using the fast Fourier transform (FFT) in this study. TRMM 3B42 rainfall estimates were first converted into a polar coordinate system using the TC center as the origin. Then, the spatial asymmetries of rainfall were examined by binning rainfall in $10 \mathrm{~km}$-wide annuli from the $\mathrm{TC}$ center to a $500 \mathrm{~km}$ radius. In each annulus, the Fourier coefficients were computed using the following equations [60]:

$$
\begin{aligned}
& a_{n}=\frac{1}{N} \sum_{i=0}^{N} R(i) \cos \left(\frac{2 \pi n i}{N}\right), \\
& b_{n}=\frac{1}{N} \sum_{i=0}^{N} R(i) \sin \left(\frac{2 \pi n i}{N}\right),
\end{aligned}
$$

TABLE 1: Landing TC six-hourly samples in different periods over each basin during 1998-2016.

\begin{tabular}{lcccc}
\hline Basin & Off-shore & Preland & High-PV & Low-PV \\
\hline ATL & 364 & 519 & 131 & 321 \\
EPA & 252 & 226 & 30 & 43 \\
NWP & 1556 & 1774 & 465 & 797 \\
NIO & 310 & 356 & 68 & 157 \\
SIO & 412 & 681 & 187 & 246 \\
SPA & 126 & 232 & 59 & 80 \\
\hline
\end{tabular}

where $R(i)$ is each of the individual rain rate estimates and $n$ is the wavenumber. $N$ is set to be 128 in this study, which is the highest wavenumber that we can resolve in this Fourier decomposition. $i$ is the index of each point. Then, the rainfall asymmetric component of wavenumber $n, R_{n}$, can be represented by

$$
R_{n}=a_{n} \cos \left(\frac{2 \pi \mathrm{ni}}{N}\right)+b_{n} \sin \left(\frac{2 \pi \mathrm{ni}}{N}\right) .
$$

Similar to [27], $R_{n}$ is not divided by the azimuthal mean rain rate (wavenumber $0, R_{0}$ ) as used in Lonfat et al. [16]. The variations of amplitudes of wavenumber 1-5 rain rate components and their amplitudes relative to the sum of wavenumbers 1-5 rain rates within the radius of $500 \mathrm{~km}$ from TC center were also calculated for the four subregions.

\section{Results}

3.1. Azimuthal Mean Rain Rate. Before comparing the rainfall asymmetry usually represented by the decomposed field of wavenumber 1, we examined how the azimuthal mean rain rates distribute radially among different basins to understand the relative amplitude of the composited field to the mean rain rate for different TC subregions. Over the open ocean (Figure 1(a)), the azimuthal mean rain rates are the largest for TCs in the SIO in the inner core region, followed by NWP, ATL, SPA, NIO, and EPA in a descending order. The locations of the peak rain rates for SIO, NWP, ATL, SPA, NIO, and EPA are about $40,40,50,50,30$, and $40 \mathrm{~km}$ from the storm center with the magnitudes of $\sim 4.8-5.2 \mathrm{~mm} \cdot \mathrm{hr}^{-1}$, receiving about three times higher rainfall than the outer region $(100-300 \mathrm{~km})$, respectively. This result is similar to the recent satellite composites by Ankur et al. [10]. The peak azimuthal mean rain rates for six basins experience a slight enhancement during the course of TCs approaching the coast and making landfall with the rain rate of $\sim 5.0-5.8 \mathrm{~mm} \cdot \mathrm{hr}^{-1}$ (Figure 1(b)). This can be explained by the fact that the surface frictional convergence between the land and ocean in landfalling TCs $[32,42]$ is consistent with previous studies [27, 30, 61, 62]. In addition, NWP TCs have the highest rain rates at all radii with the largest rain rate of $5.8 \mathrm{~m} \mathrm{~s}^{-1}$ located at $30 \mathrm{~km}$ from TC center due to stronger TC intensity in NWP than other basins. After TCs make a landfall, as shown in Figure 1(d), the rainfall intensity in all basins are significantly reduced if there is no TC-trough interaction. However, the rain rates will probably increase when the TCs are embedded in the 

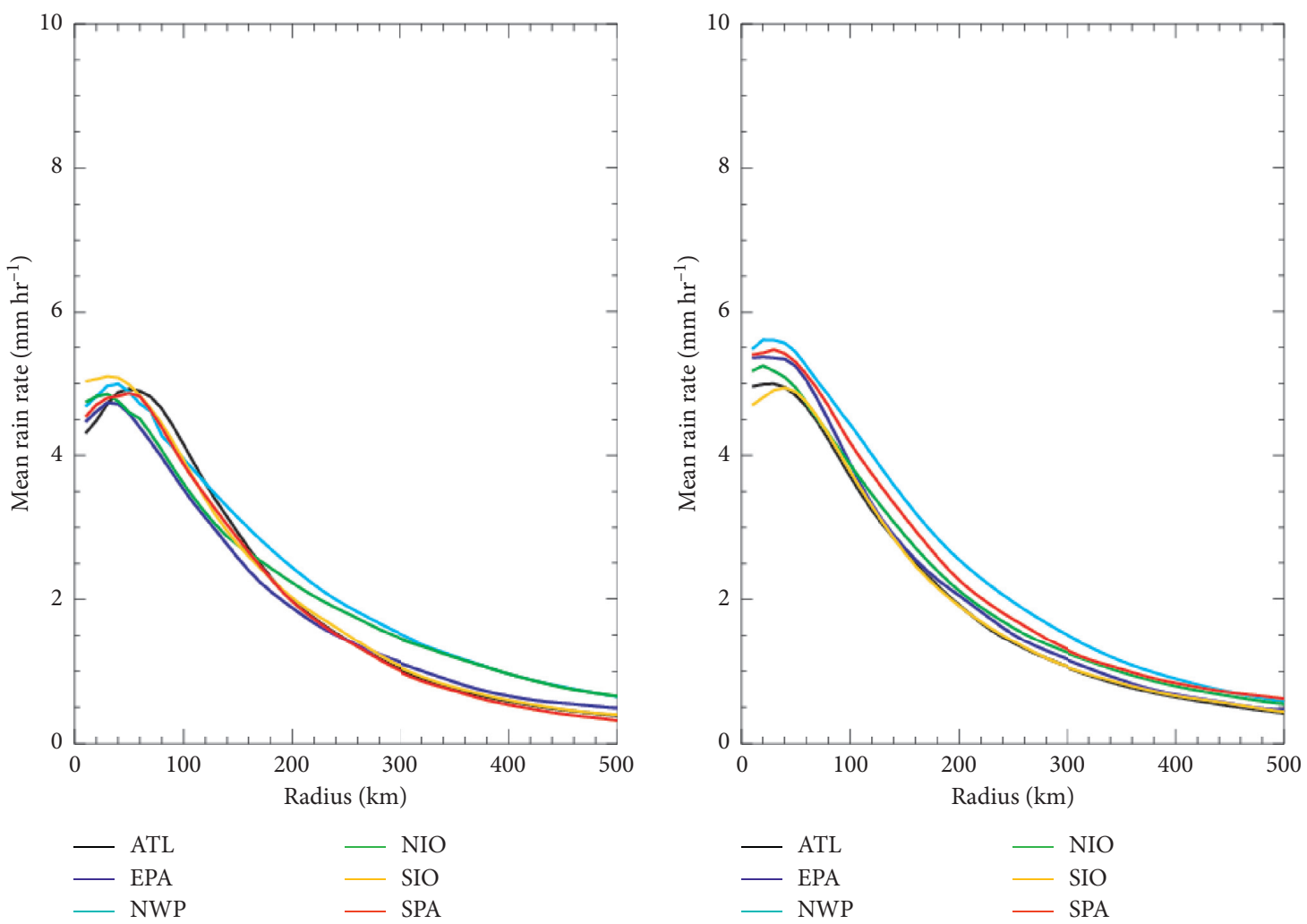

(a)
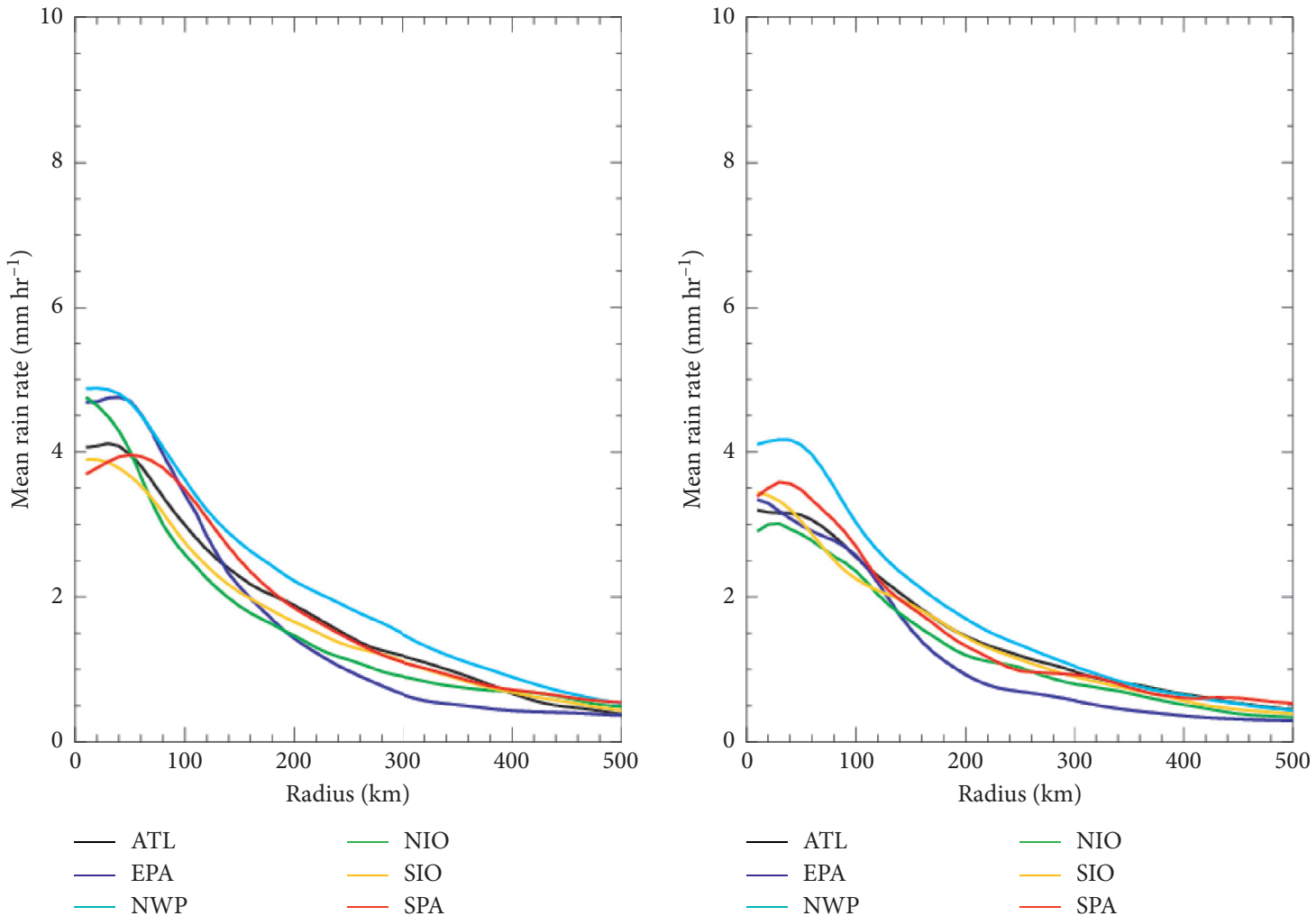

(c)

(d)

Figure 1: Mean rain rates for (a) off-shore, (b) preland, and (c) in-land under high-PV environmental condition and (d) in-land under lowPV condition over different basins. 
environment of upper-level trough systems, which is beneficial to TCs intensification (Figure 1(c)).

3.2. Rainfall Contribution Spectrum. In order to investigate the evolution of rainfall asymmetry in landfalling TCs over different basins, we calculated the amplitudes of wavenumbers 1-5 rainfall components relative to the total amplitude of wavenumbers 1-5 components over the annulus of $30-300 \mathrm{~km}$ radii during off-shore, preland, and in-land under high-PV and low-PV condition. As shown in Figure 2, in general, the amplitude of axisymmetric component rainfall was approximately $50 \%$ of the total amplitude before TCs make a landfall, which indicated that the axisymmetric component could explain about half of the variance of the total rainfall over global basins. Pei and Jiang [27] (their Figure 1) found that wavenumber 1 contributes about $40 \%$ of the total precipitation energy for the TCs over the open ocean by using the TRMM TMI $2 \mathrm{~A} 12$ dataset. In contrast, we use TRMM 3B42 dataset with more samples to analyze the TCs rainfall structure during their landfalling since the TCs rainfall pattern is becoming more asymmetric as TCs make a landfall [42].

As TCs approach the coast (preland TCs), the rainfall magnitude experiences a slight decrease by about $3 \%$, which is consistent with previous studies [32, 37, 42]. The contribution from higher wavenumbers to the total rainfall of preland TCs is slightly higher than that of off-shore TCs. This result suggests that dividing the total precipitation into different mesoscale convective systems breaks down the rainfall perturbations and creates high wavenumber components [27, 32].

After TCs make a landfall, however, the amplitude of wavenumber 1 rainfall component decreases over all basins, which is consistent with the result from previous studies $[3,35]$. In addition, wavenumber 1 component of the energy associated with high-PV condition is higher than that of preland TCs only in EPA and SIO basins (Figures 2(b) and $2(\mathrm{e})$ ), suggesting that the Rossby wave trough can play an important role in forcing the TC asymmetric rainfall and convection [63]. Alternatively, wavenumber 1 component energy with high-PV condition is higher than that with a low-PV environment condition over all basins, indicating that the upper-level trough acts to enhance the rainfall rate in landfalling TCs by the quasigeostrophic vertical motion [55]. Of note, in a low-PV environment, the orographyinduced mesoscale convective activities with high $(<1)$ wavenumber components become pronounced as the TCs pass over the topography $[30,39,43]$.

3.3. Shear-Relative Rainfall Distribution. It has been widely accepted that environmental vertical wind shear has a significant impact on the TC rainfall asymmetric distributions. Figure 3 presents the composite shear-relative rain rates for off-shore, preland, and in-land under high-PV and low-PV environmental conditions. Overall, off-shore, preland, and in-land TCs have maximum rainfall located in the downshear quadrant, indicating that VWS affects the rainfall distribution during the whole life cycle of a landfalling TC.
These general findings are consistent with previous studies $[15,17,42,43]$. Moreover, in-land TCs with high-PV have a maximum rainfall located in the downshear-left quadrant, while those with low-PV have a maximum rainfall in the downshear quadrants. In general, in-land TCs under highPV condition have a higher rain rate in the inner $200 \mathrm{~km}$ region than that of in-land TCs under low-PV condition. Previous studies suggested that the contribution of terrains to the TCs rainfall asymmetries enhancement was relatively small [32, 42]. This indicates that the upper-tropospheric PV anomaly can play a role in the rainfall rate maintenance in landfalling TCs by quasigeostrophic vertical motion, modulating PV redistribution towards the surface through diabatic heating [55]. To illustrate the location of maximum rainfall, Figure 4 shows the composite shear-relative wavenumber 1 rainfall asymmetry in the four subregions over global oceanic basins. Remarkably similar to the result in Figure 3, the maximum wavenumber 1 rainfall rotated from downshear-left before landfall to downshear after landfall.

\section{Summary and Conclusions}

Nineteen years (1998-2016) of TRMM satellite 3B42 rain rates are employed to examine the shear-relative rainfall asymmetries of landfalling TCs over global oceanic basins using the fast Fourier transform (FFT) analysis in this study. It is found that the wavenumber 1 perturbation is the largest in the energy spectrum to contribute half of the total perturbation energy of total TC rainfall. In contrast, Pei and Jiang [27] found that wavenumber 1 perturbation contributes about $37 \%$ of the total precipitation energy for the TCs over the open ocean. Our result supports the statistics that the TC rainfall asymmetry increases when TCs make a landfall in South China and Southeast United States in the presence of upper-tropospheric troughs $[32,42]$. It is necessary to analyze the effects of upper-tropospheric troughs on the asymmetric rainfall redistribution during the life cycle of landfalling TCs in different basins.

To investigate the impact of TC-trough configuration on the landfalling TC rainfall intensity and distribution, the landfalling TCs are binned into subregions under high-PV anomaly and low-PV anomaly environmental conditions. In general, the azimuthal mean rain rates of landfalling TCs under the high-PV condition are greater than those under the low-PV condition. This result indicates that the upper-tropospheric troughs baroclinic processes tend to play a role in the rainfall maintenance associated with landfalling TCs. Besides, our results show that the maximum TC rain rate tends to be located at the downshear-left (downshear) quadrant under the high (low)-potential vorticity conditions, suggesting that the VWS associated with upper-level trough is the dominant factor in determining the rainfall asymmetry in landfalling TCs.

It is known that the upper-level trough is an important environmental cause of TCs circulation enhancement $[56,59]$. This study investigates the role of upper-tropospheric troughs on the rainfall intensity and distribution after TCs make a landfall over the six TC-prone basins. The 


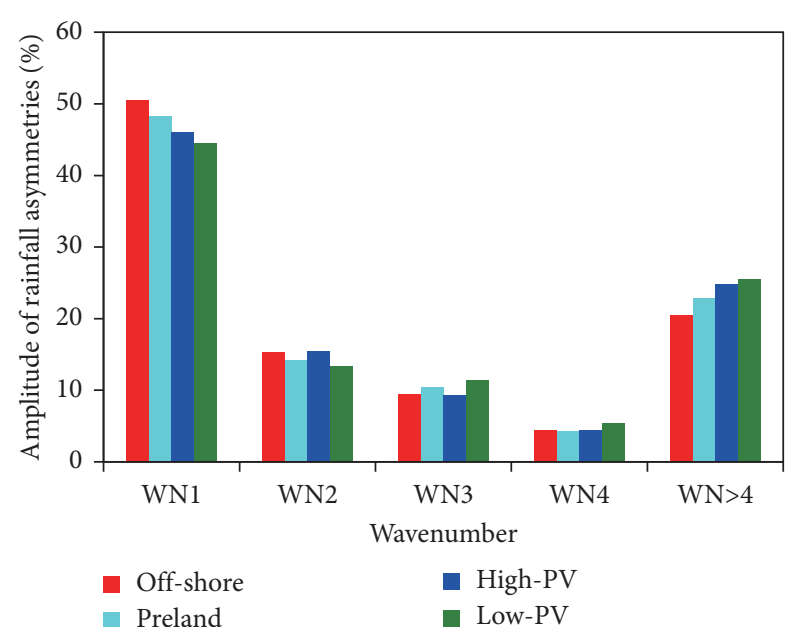

(a)

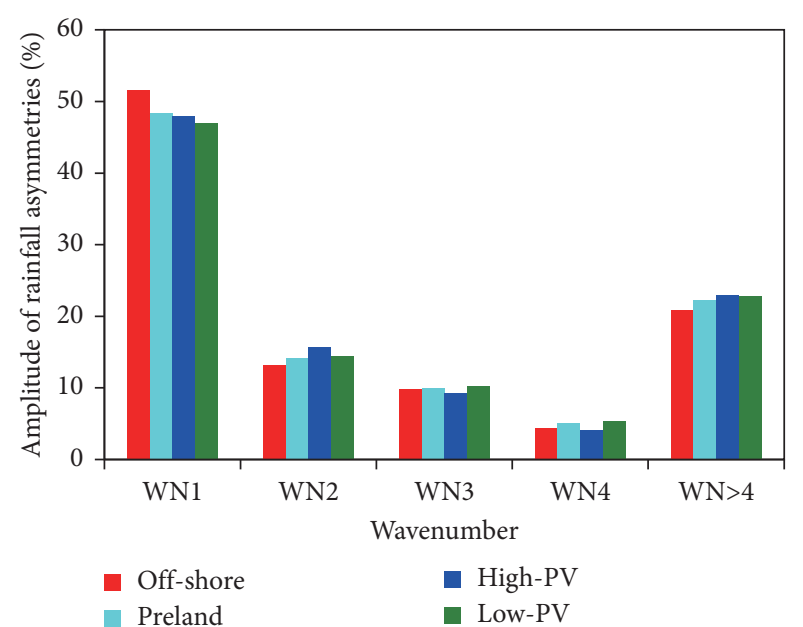

(c)

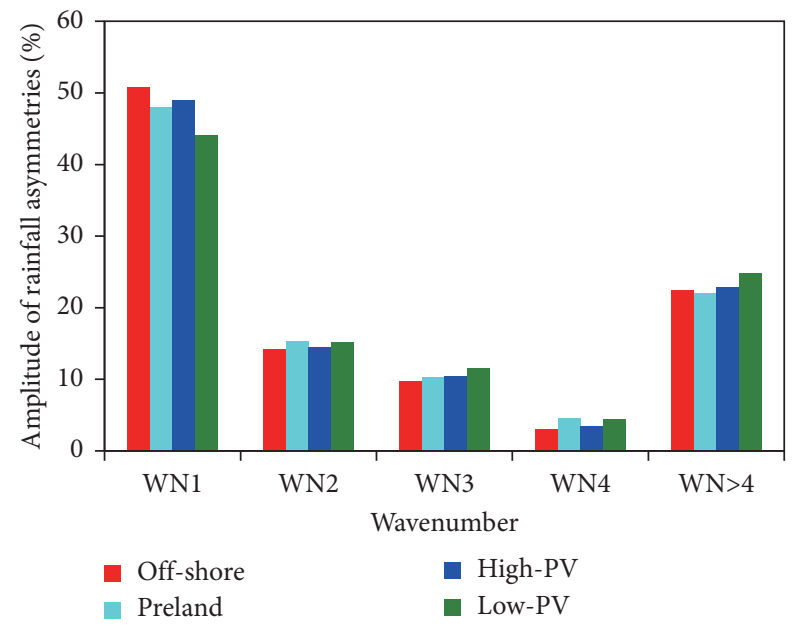

(e)

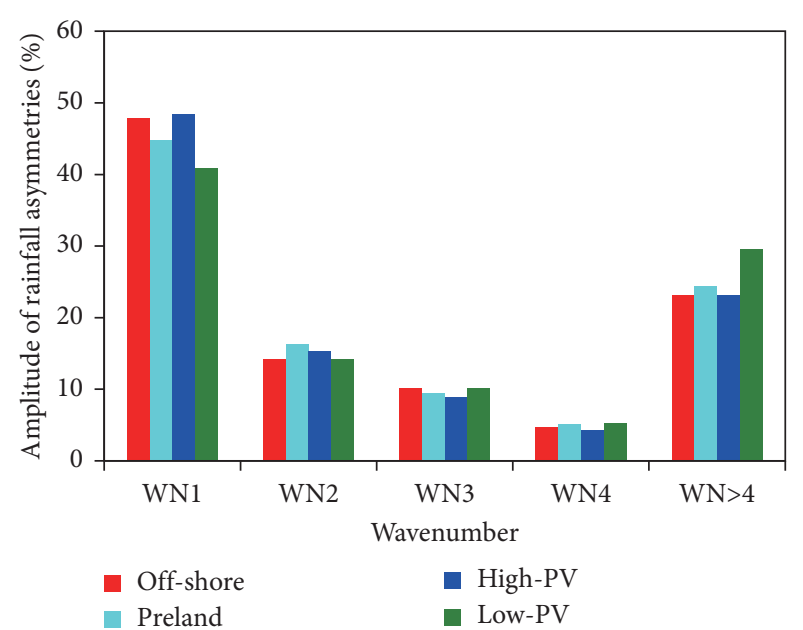

(b)

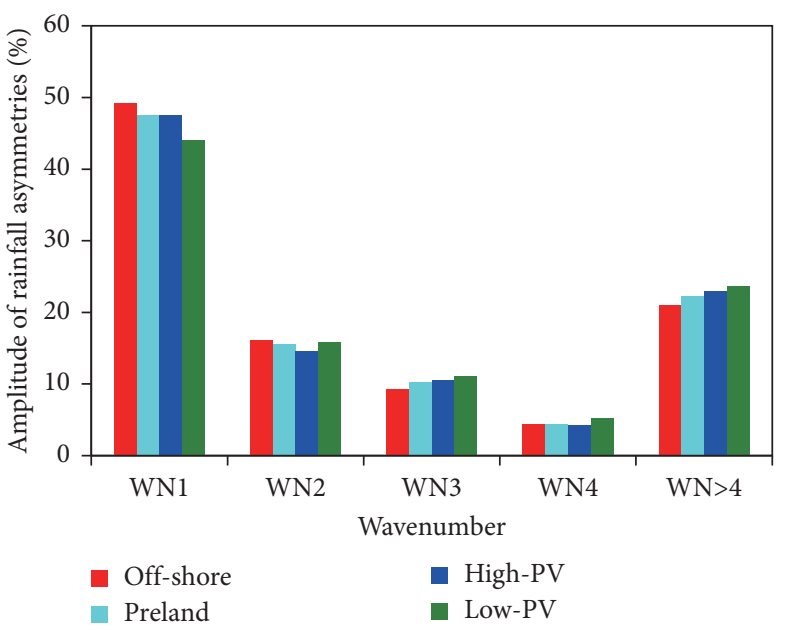

(d)

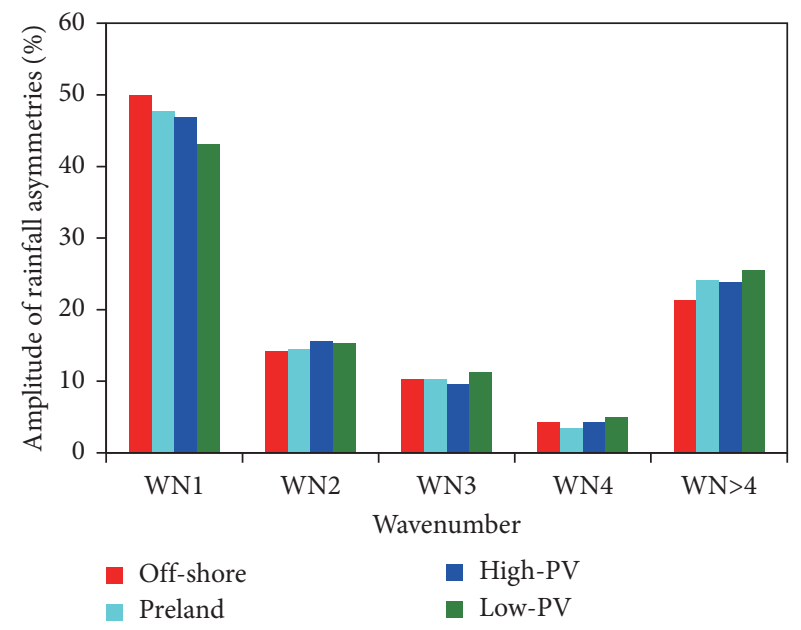

(f)

FIgURE 2: The amplitudes of wavenumbers 1,2,3, 4, and 5 asymmetric components of rain rate relative to the total rain rates over the annulus from 30 to $300 \mathrm{~km}$ from the TC center for (a) ATL, (b) EPA, (c) NWP, (d) NIO, (e) SIO, and (f) SPA basins during the off-shore, preland, and in-land under high-PV and low-PV conditions. 

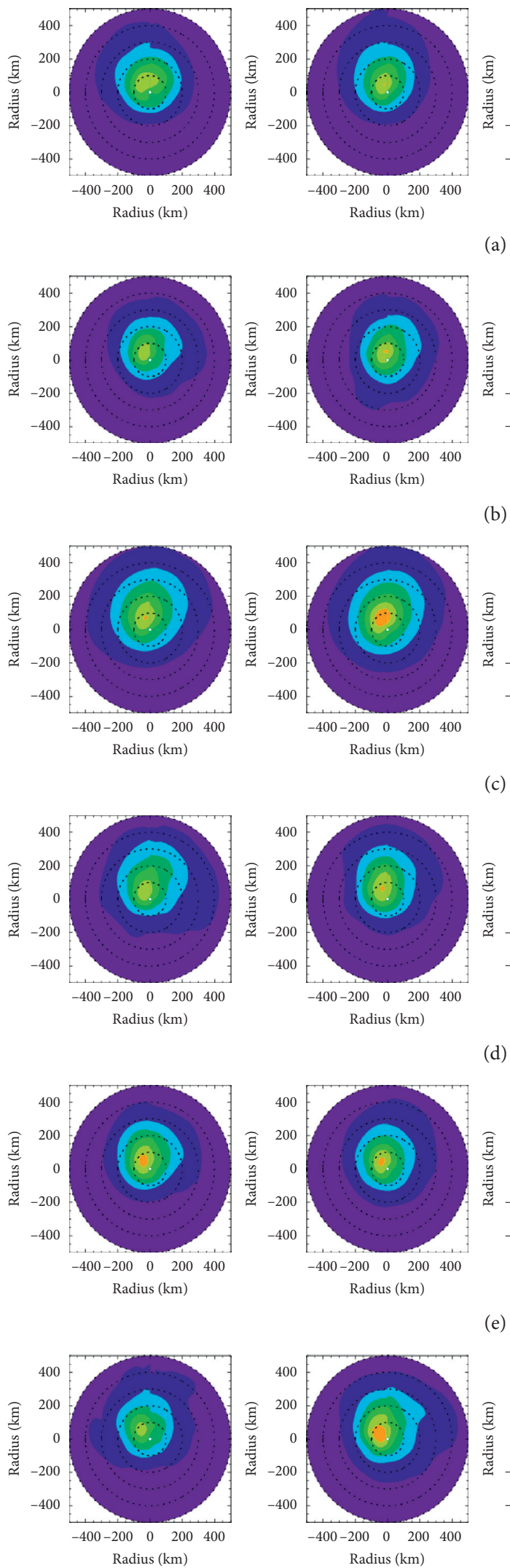

(a)

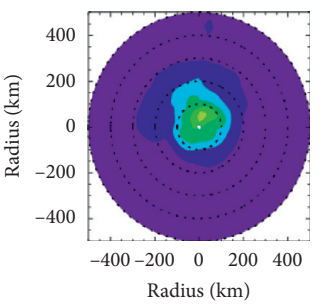

(b)

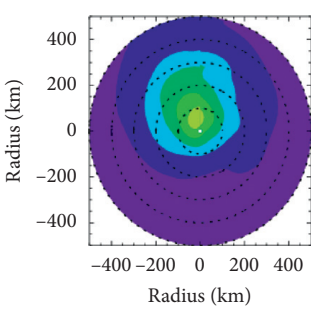

(c)

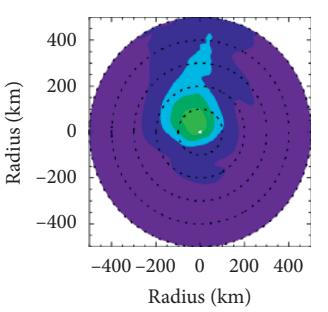

(d)

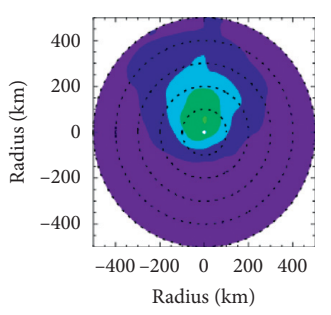

(e)
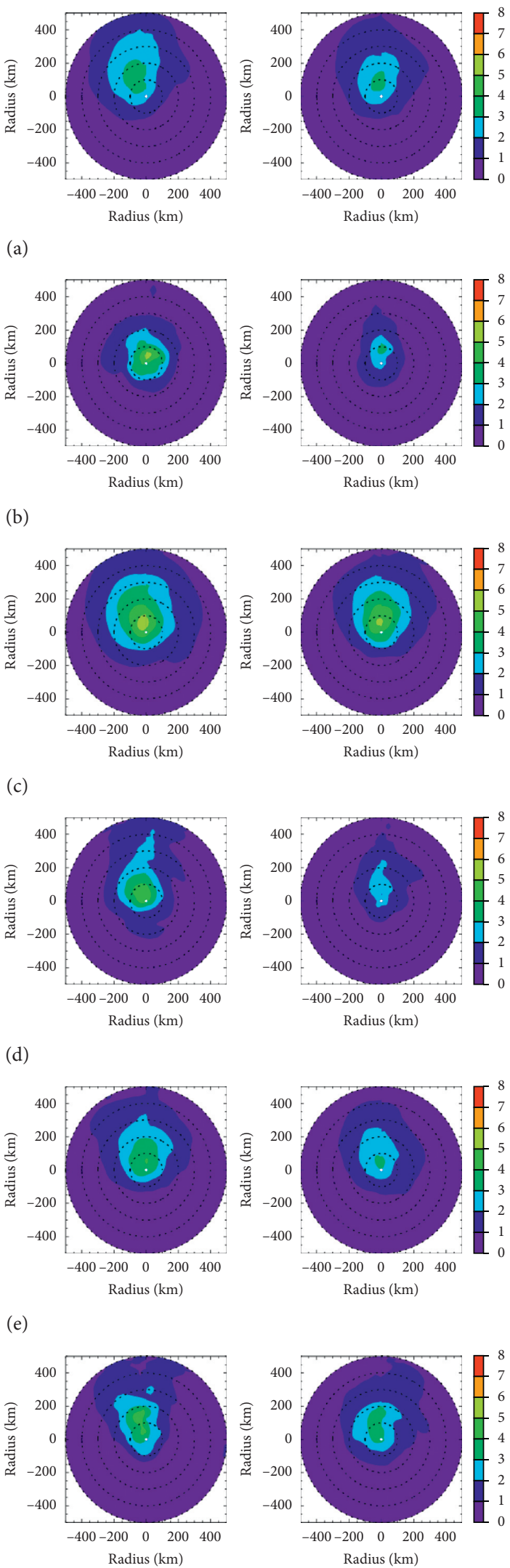

(f)

FIGURE 3: The composite shear-relative rain rate $\left(\mathrm{mm} \mathrm{hr}^{-1}\right)$ for (I) off-shore, (II) preland, (III) in-land with high-PV, and (IV) in-land with low-PV over (a) ATL, (b) EPA, (c) NWP, (d) NIO, (e) SIO, and (f) SPA. The shear direction rotated clockwise with $0^{\circ}$ pointing to the north. 

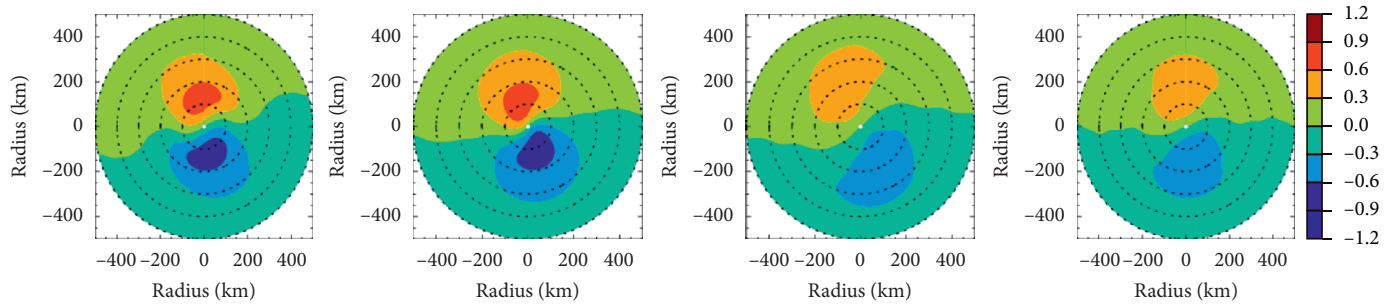

(a)
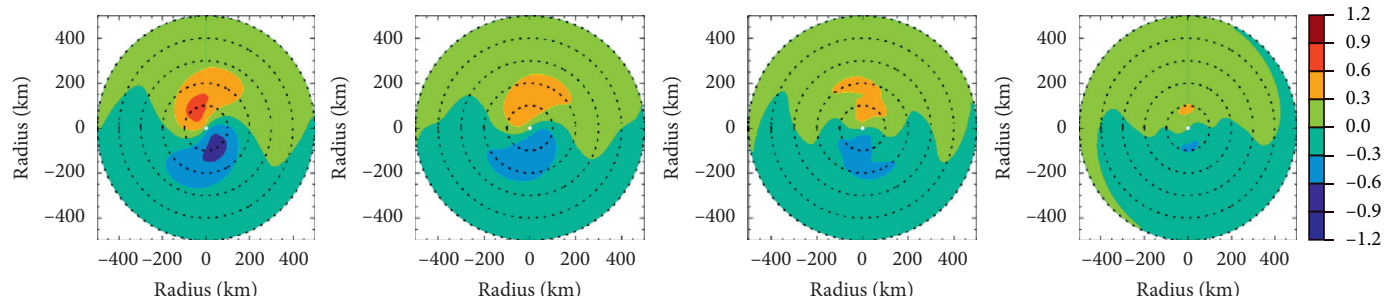

(b)
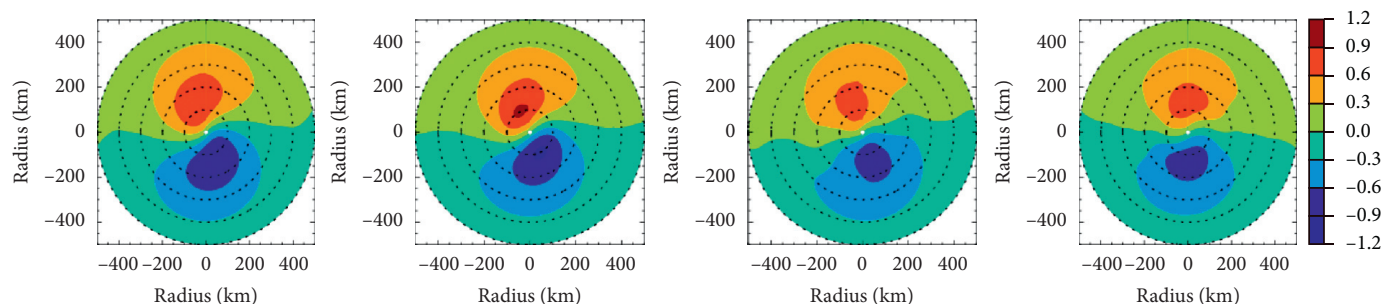

(c)
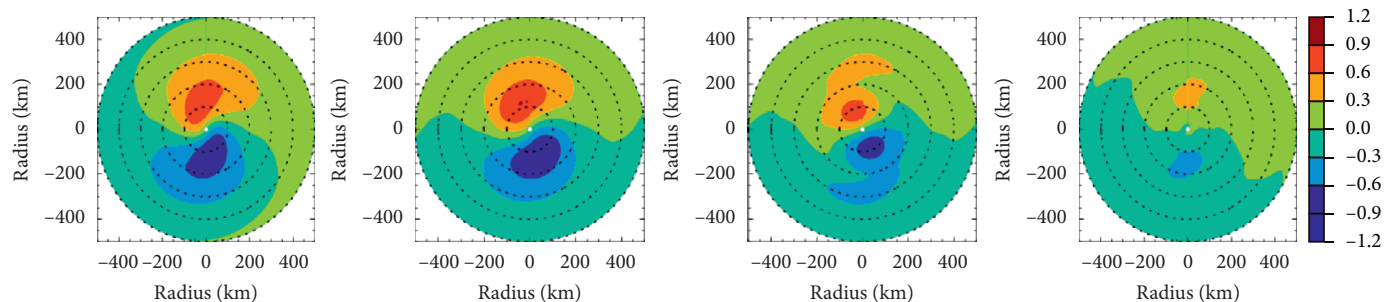

(d)
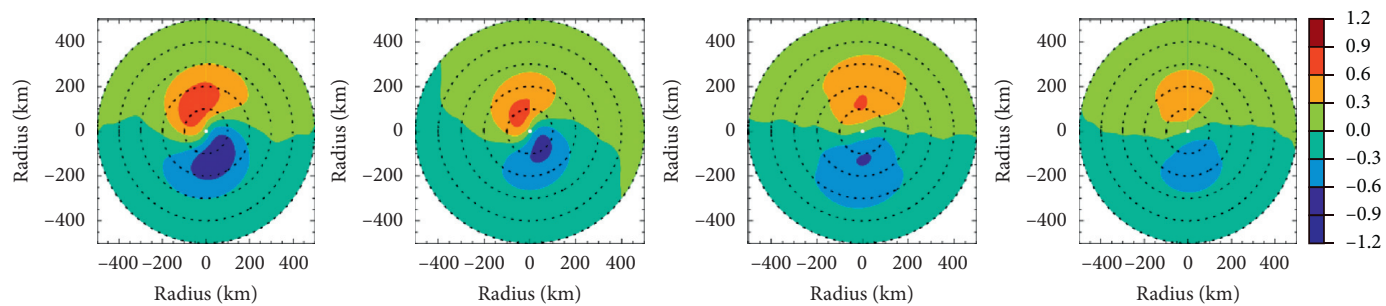

(e)
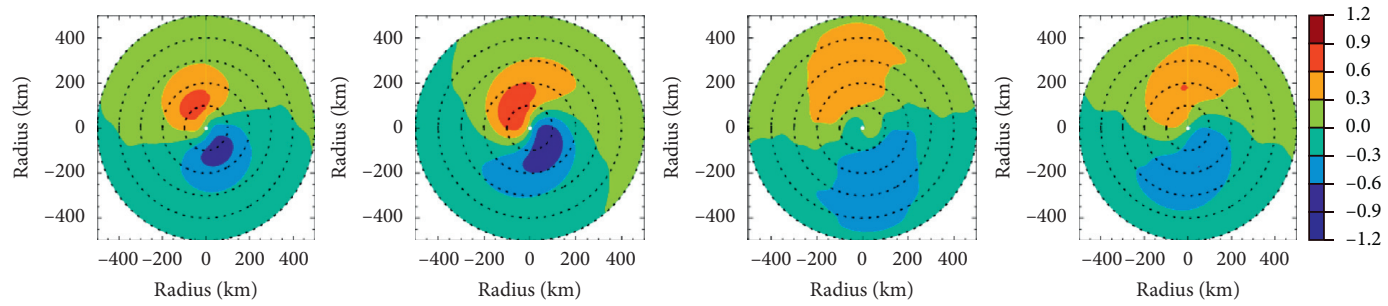

(f)

Figure 4: The composite shear-relative wavenumber 1 asymmetry for (I) off-shore, (II) preland, (III) in-land with high-PV, and (IV) in-land with low-PV over (a) ATL, (b) EPA, (c) NWP, (d) NIO, (e) SIO, and (f) SPA. The shear direction rotated clockwise with $0^{\circ}$ pointing to the north. 
asymmetric rainfall tends to decrease less if there is an interaction between TCs and upper-level troughs located at the upstream of TCs over land. However, one of the limitations of this study is not being able to fully explain the relationship between TC rainfall and its characteristics relative to the upper-level trough or other attributable factors with TRMM data, which can be addressed in the future when additional data from numerical models or advanced observing instruments become available.

\section{Data Availability}

All TRMM satellite 3B42 rainfall estimate datasets used in our research are open to the public.

\section{Conflicts of Interest}

The authors declare that there are no conflicts of interest regarding the publication of this paper.

\section{Acknowledgments}

The portion of this work by the first and third authors were supported by the National Natural Science Foundation of China (grant nos. 41875070 and 41365005) and Hainan Key Cooperation Program (grant no. ZDYF2019213).

\section{References}

[1] R. L. Elsberry, "Advances in research and forecasting of tropical cyclones from 1963-2013," Asia-Pacific Journal of Atmospheric Sciences, vol. 50, no. 1, pp. 3-16, 2014.

[2] E. N. Rappaport, "Fatalities in the United States from atlantic tropical cyclones: new data and interpretation," Bulletin of the American Meteorological Society, vol. 95, no. 3, pp. 341-346, 2014.

[3] Z. Yu, Y. Wang, and H. Xu, "Observed rainfall asymmetry in tropical cyclones making landfall over China," Journal of Applied Meteorology and Climatology, vol. 54, no. 1, pp. 117-136, 2015.

[4] R. L. Elsberry, "Predicting Hurricane landfall precipitation: optimistic and pessimistic views from the symposium on precipitation extremes," Bulletin of the American Meteorological Society, vol. 83, pp. 1333-1340, 2002.

[5] K. Cheung, Z. Yu, R. L. Elsberry et al., "Recent advances in research and forecasting of tropical cyclone rainfall," Tropical Cyclone Research and Review, vol. 7, pp. 106-127, 2018.

[6] F. D. Marks, "Evolution of the structure of precipitation in Hurricane allen (1980)," Monthly Weather Review, vol. 113, no. 6, pp. 909-930, 1985.

[7] R. W. Burpee and M. L. Black, "Temporal and spatial variations of rainfall near the centers of two tropical cyclones," Monthly Weather Review, vol. 117, no. 10, pp. 2204-2218, 1989.

[8] L. J. Shapiro, "The asymmetric boundary layer flow under a translating Hurricane," Journal of the Atmospheric Sciences, vol. 40, no. 8, pp. 1984-1998, 1983.

[9] K. L. Corbosiero and J. Molinari, "The relationship between storm motion, vertical wind shear, and convective asymmetries in tropical cyclones," Journal of the Atmospheric Sciences, vol. 60, no. 2, pp. 366-376, 2003.

[10] K. Ankur, N. K. R. Busireddy, K. K. Osuri, and D. Niyogi, "On the relationship between intensity changes and rainfall distribution in tropical cyclones over the North Indian Ocean," International Journal of Climatology, vol. 40, no. 4, pp. 2015-2025, 2019.

[11] W. M. Frank and E. A. Ritchie, "Effects of environmental flow upon tropical cyclone structure," Monthly Weather Review, vol. 127, no. 9, pp. 2044-2061, 1999.

[12] W. M. Frank and E. A. Ritchie, "Effects of vertical wind shear on the intensity and structure of numerically simulated hurricanes," Monthly Weather Review, vol. 129, no. 9, pp. 2249-2269, 2001.

[13] S. C. Jones, "The evolution of vortices in vertical shear. I: initially barotropic vortices," Quarterly Journal of the Royal Meteorological Society, vol. 121, no. 524, pp. 821-851, 1995.

[14] J. Molinari, P. Dodge, D. Vollaro, K. L. Corbosiero, and F. Marks, "Mesoscale Aspects of the downshear reformation of a tropical cyclone," Journal of the Atmospheric Sciences, vol. 63, no. 1, pp. 341-354, 2006.

[15] K. L. Corbosiero and J. Molinari, "The effects of vertical wind shear on the distribution of convection in tropical cyclones," Monthly Weather Review, vol. 130, no. 8, pp. 2110-2123, 2002.

[16] M. Lonfat, F. D. Marks, and S. S. Chen, "Precipitation distribution in tropical cyclones using the tropical rainfall measuring mission (TRMM) microwave imager: a global perspective," Monthly Weather Review, vol. 132, no. 7, pp. 1645-1660, 2004.

[17] D. J. Cecil, "Satellite-derived rain rates in vertically sheared tropical cyclones," Geophysical Research Letters, vol. 34, 2007.

[18] S. S. Chen, J. A. Knaff, and F. D. Marks, "Effects of vertical wind shear and storm motion on tropical cyclone rainfall asymmetries deduced from TRMM," Monthly Weather Review, vol. 134, no. 11, pp. 3190-3208, 2006.

[19] R. Rogers, S. Chen, J. Tenerelli, and H. Willoughby, “A numerical study of the impact of vertical shear on the distribution of rainfall in Hurricane bonnie (1998)," Monthly Weather Review, vol. 131, no. 8, pp. 1577-1599, 2003.

[20] L. F. Bosart, C. S. Velden, W. E. Bracken, J. Molinari, and P. G. Black, "Environmental influences on the rapid intensification of Hurricane opal (1995) over the gulf of Mexico," Monthly Weather Review, vol. 128, no. 2, pp. 322-352, 2000.

[21] S. Shu, F. Zhang, J. Ming, and Y. Wang, "Environmental influences on the intensity changes of tropical cyclones over the western North Pacific," Atmospheric Chemistry and Physics, vol. 14, no. 12, pp. 6329-6342, 2014.

[22] S. Shu and L. Wu, "Analysis of the influence of Saharan air layer on tropical cyclone intensity using AIRS/Aqua data," Geophysical Research Letters, vol. 36, 2009.

[23] W. A. Komaromi and J. D. Doyle, "On the dynamics of tropical cyclone and trough interactions," Journal of the Atmospheric Sciences, vol. 75, no. 8, pp. 2687-2709, 2018.

[24] D. Deng and E. A. Ritchie, "Rainfall characteristics of recurving tropical cyclones over the western north pacific," Journal of Climate, vol. 31, pp. 575-592, 2017.

[25] E. B. Rodgers, S. W. Chang, and H. F. Pierce, "A satellite observational and numerical study of precipitation characteristics in western North Atlantic tropical cyclones," Journal of Applied Meteorology, vol. 33, no. 2, pp. 129-139, 1994.

[26] P. Zhu, K. Menelaou, and Z. Zhu, "Impact of subgrid-scale vertical turbulent mixing on eyewall asymmetric structures and mesovortices of hurricanes," Quarterly Journal of the Royal Meteorological Society, vol. 140, no. 679, pp. 416-438, 2014.

[27] Y. Pei and H. Jiang, "Quantification of precipitation asymmetries of tropical cyclones using 16-year TRMM 
observations," Journal of Geophysical Research: Atmospheres, vol. 123, pp. 8091-8114, 2018.

[28] Y. Wang and G. J. Holland, "Tropical cyclone motion and evolution in vertical shear," Journal of the Atmospheric Sciences, vol. 53, no. 22, pp. 3313-3332, 1996.

[29] M. Ueno, "Observational analysis and numerical evaluation of the effects of vertical wind shear on the rainfall asymmetry in the Typhoon inner-core region," Journal of the Meteorological Society of Japan, vol. 85, no. 2, pp. 115-136, 2007.

[30] Z. Yu, Y. Wang, H. Xu et al., "On the relationship between intensity and rainfall distribution in tropical cyclones making landfall over China," Journal of Applied Meteorology and Climatology, vol. 56, no. 10, pp. 2883-2901, 2017.

[31] K. S. Liu, J. C. L. Chan, W. C. Cheng, S. L. Tai, and P. W. Wong, "Distribution of convection associated with tropical cyclones making landfall along the South China coast," Meteorology and Atmospheric Physics, vol. 97, no. 1-4, pp. 57-68, 2007.

[32] J. C. L. Chan, K. S. Liu, S. E. Ching, and E. S. T. Lai, "Asymmetric distribution of convection associated with tropical cyclones making landfall along the south China coast," Monthly Weather Review, vol. 132, no. 10, pp. 2410-2420, 2004.

[33] J. Liu, F. Zhang, and Z. Pu, "Numerical simulation of the rapid intensification of Hurricane Katrina (2005): sensitivity to boundary layer parameterization schemes," Advances in Atmospheric Sciences, vol. 34, no. 4, pp. 482-496, 2017.

[34] K. T. F. Chan, J. C. L. Chan, and W. K. Wong, "Rainfall asymmetries of landfalling tropical cyclones along the South China coast," Meteorological Applications, vol. 26, no. 2, pp. 213-220, 2019.

[35] D. Wu, K. Zhao, B. J.-D. Jou, and W.-C. Lee, "Radar observation of precipitation asymmetries in tropical cyclones making landfall on east China coast," Tropical Cyclone Research and Review, vol. 2, pp. 81-95, 2013.

[36] G. Wen, G. Huang, H. Huang, C. Liu, and X. Bi, "Observed rainfall asymmetry of tropical cyclone in the process of making landfall in Guangdong, south China," International Journal of Climatology, vol. 39, no. 7, pp. 3379-3395, 2019.

[37] X. Feng and S. Shu, "How do weak tropical cyclones produce heavy rainfall when making landfall over China," Journal of Geophysical Research: Atmospheres, vol. 123, pp. 11,83011,848, 2018.

[38] S. Shu, X. Feng, and Y. Wang, "Essential role of synoptic environment on rainfall distribution of landfalling tropical cyclones over China," Journal of Geophysical Research: Atmospheres, vol. 123, pp. 11,285-11,306, 2018.

[39] J. C. DeHart and R. A. Houze, "Orographic modification of precipitation processes in Hurricane karl (2010)," Monthly Weather Review, vol. 145, no. 10, pp. 4171-4186, 2017.

[40] X. Bao, N. E. Davidson, H. Yu et al., "Diagnostics for an extreme rain event near shanghai during the landfall of Typhoon fitow (2013)," Monthly Weather Review, vol. 143, no. 9, pp. 3377-3405, 2015.

[41] E. Atallah, L. F. Bosart, and A. R. Aiyyer, "Precipitation distribution associated with landfalling tropical cyclones over the eastern United States," Monthly Weather Review, vol. 135, no. 6, pp. 2185-2206, 2007.

[42] W. Xu, H. Jiang, and X. Kang, "Rainfall asymmetries of tropical cyclones prior to, during, and after making landfall in South China and Southeast United States," Atmospheric Research, vol. 139, pp. 18-26, 2014.

[43] M. T. Wingo and D. J. Cecil, "Effects of vertical wind shear on tropical cyclone precipitation," Monthly Weather Review, vol. 138, no. 3, pp. 645-662, 2010.
[44] X. Ge, T. Li, and M. Peng, "Effects of vertical shears and midlevel dry air on tropical cyclone developments*," Journal of the Atmospheric Sciences, vol. 70, no. 12, pp. 3859-3875, 2013.

[45] X. Li, N. E. Davidson, Y. Duan, K. J. Tory, Z. Sun, and Q. Cai, "Analysis of an ensemble of high-resolution WRF simulations for the rapid intensification of super typhoon rammasun (2014)," Advances in Atmospheric Sciences, vol. 37, pp. 181204, 2020.

[46] H. Jiang, J. B. Halverson, and J. Simpson, "On the differences in storm rainfall from hurricanes isidore and lili. Part I: satellite observations and rain potential," Weather and Forecasting, vol. 23, no. 1, pp. 29-43, 2008.

[47] Z. Yu, H. Yu, P. Chen, C. Qian, and C. Yue, "Verification of tropical cyclone-related satellite precipitation estimates in mainland China," Journal of Applied Meteorology and Climatology, vol. 48, no. 11, pp. 2227-2241, 2009.

[48] Y. Chen, E. E. Ebert, K. J. E. Walsh, and N. E. Davidson, "Evaluation of TMPA 3B42 daily precipitation estimates of tropical cyclone rainfall over Australia," Journal of Geophysical Research: Atmospheres, vol. 118, pp. 11,966-11,978, 2013.

[49] T. Zhao and A. Yatagai, "Evaluation of TRMM 3B42 product using a new gauge-based analysis of daily precipitation over China," International Journal of Climatology, vol. 34, no. 8, pp. 2749-2762, 2014.

[50] D. P. Dee, S. M. Uppala, A. J. Simmons et al., “The ERAInterim reanalysis: configuration and performance of the data assimilation system," Quarterly Journal of the Royal Meteorological Society, vol. 137, no. 656, pp. 553-597, 2011.

[51] D. P. Dee and S. Uppala, "Variational bias correction of satellite radiance data in the ERA-Interim reanalysis," Quarterly Journal of the Royal Meteorological Society, vol. 135, no. 644, pp. 1830-1841, 2009.

[52] J. P. Zagrodnik and H. Jiang, "Rainfall, convection, and latent heating distributions in rapidly intensifying tropical cyclones," Journal of the Atmospheric Sciences, vol. 71, no. 8, pp. 2789-2809, 2014.

[53] C. Tao, H. Jiang, and J. Zawislak, "The relative importance of stratiform and convective rainfall in rapidly intensifying tropical cyclones," Monthly Weather Review, vol. 145, no. 3, pp. 795-809, 2017.

[54] D. A. Hence and R. A. Houze Jr, "Vertical structure of tropical cyclone rainbands as seen by the TRMM precipitation radar," Journal of the Atmospheric Sciences, vol. 69, no. 9, pp. 26442661, 2012.

[55] M. S. Fischer, B. H. Tang, and K. L. Corbosiero, "Assessing the influence of upper-tropospheric troughs on tropical cyclone intensification rates after genesis," Monthly Weather Review, vol. 145, no. 4, pp. 1295-1313, 2017.

[56] J. Molinari, S. Skubis, and D. Vollaro, "External influences on Hurricane intensity. Part III: potential vorticity structure," Journal of the Atmospheric Sciences, vol. 52, no. 20, pp. 3593-3606, 1995.

[57] M. DeMaria, J. A. Knaff, and B. H. Connell, "A tropical cyclone genesis parameter for the tropical atlantic," Weather and Forecasting, vol. 16, no. 2, pp. 219-233, 2001.

[58] M.-D. Leroux, M. Plu, D. Barbary, F. Roux, and P. Arbogast, "Dynamical and physical processes leading to tropical cyclone intensification under upper-level trough forcing," Journal of the Atmospheric Sciences, vol. 70, no. 8, pp. 2547-2565, 2013.

[59] C. M. Peirano, K. L. Corbosiero, and B. H. Tang, "Revisiting trough interactions and tropical cyclone intensity change," Geophysical Research Letters, vol. 43, no. 10, pp. 5509-5515, 2016. 
[60] R. B. Stull, An Introduction to Boundary Layer Meteorology, University of British, Columbia, SC, USA, 1988.

[61] H. Jiang and E. J. Zipser, "Contribution of tropical cyclones to the global precipitation from eight seasons of TRMM data: regional, seasonal, and interannual variations," Journal of Climate, vol. 23, no. 6, pp. 1526-1543, 2010.

[62] H. Jiang, C. Liu, and E. J. Zipser, "A TRMM-based tropical cyclone cloud and precipitation feature database," Journal of Applied Meteorology and Climatology, vol. 50, no. 6, pp. 1255-1274, 2011.

[63] L. Huaman, C. Schumacher, and G. N. Kiladis, "Eastwardpropagating disturbances in the tropical pacific," Monthly Weather Review, vol. 148, no. 9, pp. 3713-3728, 2020. 